\title{
Thermal Degradation of Polymers At Low Rates
}

\author{
Samuel L. Madorsky
}

\begin{abstract}
In measuring the rates of thermal degradation of polymers at constant temperatures in the range of $200^{\circ}$ to $500^{\circ} \mathrm{C}$, one encounters a distortion of the initial parts of the rate curves during the time required to heat the specimen to the pyrolysis temperature. This distortion has been largely overcome by using a new apparatus, based on an electronic balance, in which the degradation of the specimen is carried out at very low rates. The apparatus is equipped with an electronic thermostat that controls the temperature to within $\pm 0.1^{\circ} \mathrm{C}$, and also with an automatic recorder that measures both the temperature and the loss of weight of the specimen. Pyrolysis experiments were carried out in a vacuum in this apparatus on pure specimens of polystyrene, poly ( $\alpha$-methylstyrene), polymethylene, high-molecular-weight polyethylene, and low-molecular-weight polyethylene. The initial rates of degradation, in percent of sample per minute, varied from 0.008 to 0.095 . Except for the initial parts of the rate curves, in some cases up to about 30 percent loss of weight, the rate curves at low rates resemble closely those previously obtained at high rates of degradation.
\end{abstract}

\section{Introduction}

Studies on rates of thermal degradation of polymers in a vacuum by the loss-of-weight method have been carried out at the National Bureau of Standards for a number of years. The method $[1,2]^{2}$ consisted in heating a 4 to $6 \mathrm{mg}$ sample of polymer in a platinum crucible suspended from a tungsten spring balance $[1,3]$ and observing at intervals the loss of weight sustained by the sample, as indicated by the position of a crossline on the extension of the spring. For convenience, the rate experiments were usually planned to be completed within about 8 to 9 hrs. This placed a lower limit on the temperature of operation. In the range $250^{\circ}$ to $500^{\circ} \mathrm{C}$ used in these studies it usually took about $15 \mathrm{~min}$ to heat the polymer sample from room temperature to that required in a given experiment. Some vaporization of the sample, in some cases [2] as much as 30 percent of its weight, took place during this heating-up period. Constancy of temperature in any given experiment was a required condition in all the rate studies. The initial loss thus caused a distortion of the initial part of the rate curve and masked the true picture of the initiation of thermal degradation.

This difficulty could be largely overcome by carrying out the rate experiments for longer periods of time at lower temperatures so that the initial loss of sample would be reduced to as low a percentage as practicable. However, continuous operation for long periods of time suggests the use of automatic recording of loss of weight of sample. The spring balance did not lend itself easily to automatic recording.

A new apparatus for the study of rates of thermal degradation of polymers has been designed and constructed. It records continuously and automatically time, temperature, and weight of the polymer sample undergoing decomposition. This new apparatus was used in a study of thermal degradation at

${ }_{1}$ Paper presented at the 134th National Meeting of the American Chemical Society in Chicago, Ill., Sept. 7-12, 1958.

2 Figures in brackets indicate the literature references at the end of this paper. low rates of several polymers. The polymers selected for this study were: Polystyrene, which yields both monomer and larger molecular fragments; poly ( $\alpha$-methylstyrene), which yields monomer exclusively; and nonbranched and branched polyethylenes, which yield a spectrum of fragments containing from 1 to $n$ carbons.

\section{Apparatus and Experimental Procedure}

The elements of the new apparatus (exclusive of the vacuum system) are shown diagramatically in figure 1, and the whole assembly is shown photographically in figure $2 .^{3}$ The equipment is built around an electronic microbalance, which is shown in figure 1 in two parts: $A$, the balance; and $B$, the electronic unit. From the arm $\mathrm{P}$ of the balance a crucible Q containing the polymer sample is suspended within the lower furnace $\mathrm{F}$. The function of the upper furnace $\mathrm{E}$ is described later in this paper. The output of the recording balance is fed into one channel of a three-channel recording potentiometer C. The temperature of the furnace $\mathrm{F}$ is controlled to about $\pm 0.1^{\circ} \mathrm{C}$ by an electronic thermostat $J$, which senses the furnace temperature by means of a platinum resistance thermometer $\mathrm{T}$ built into the furnace. ${ }^{4}$

The temperature of the crucible is measured by means of a thermocouple $\mathrm{R}$ located directly beneath the crucible, and the output of this thermocouple is fed through the potentiometer buckout D to a second channel of the recording potentiometer C. Portable potentiometer $\mathrm{U}$ is used to check the temperature of thermocouple $R$. Thus, a continuous record of the crucible temperature, as well as of the weight of the sample, is provided on the same sheet. 'The third channel of the recorder is used to monitor the temperature of either the lower furnace $\mathrm{F}$ or the upper furnace $\mathrm{E}$ by means of a thermocouple $\mathrm{S}$,

3 The author is indebted to M. Morse of the Electronic Section for his help in the design and construction of some of the electronic parts of the apparatus. ${ }_{4}^{4}$ Except for some details which are described, furnaces $\mathrm{E}$ and $\mathrm{F}$ are similar to those used in connection with the spring balance in previous work [1]. 


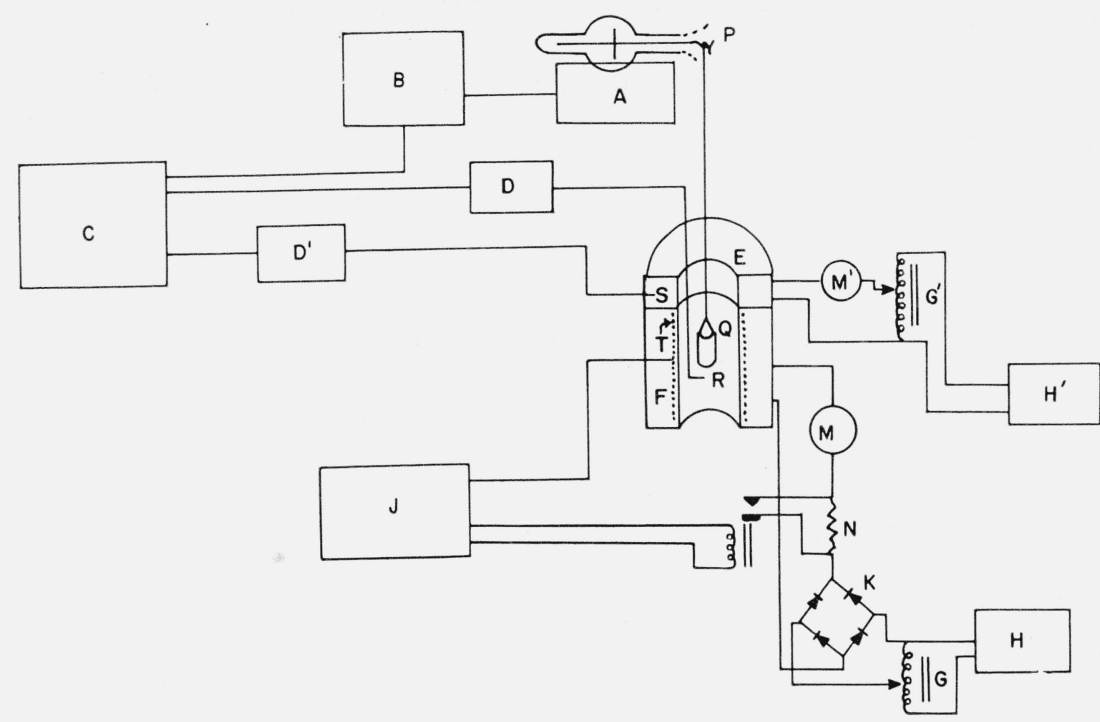

Figure 1. Block diagram of polymer degradation equipment.

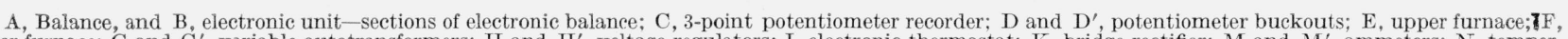

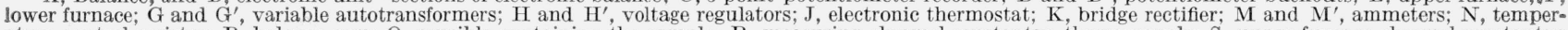

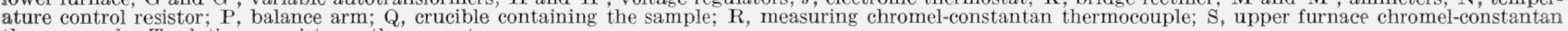
thermocouple; T, platinum resistance thermometer.

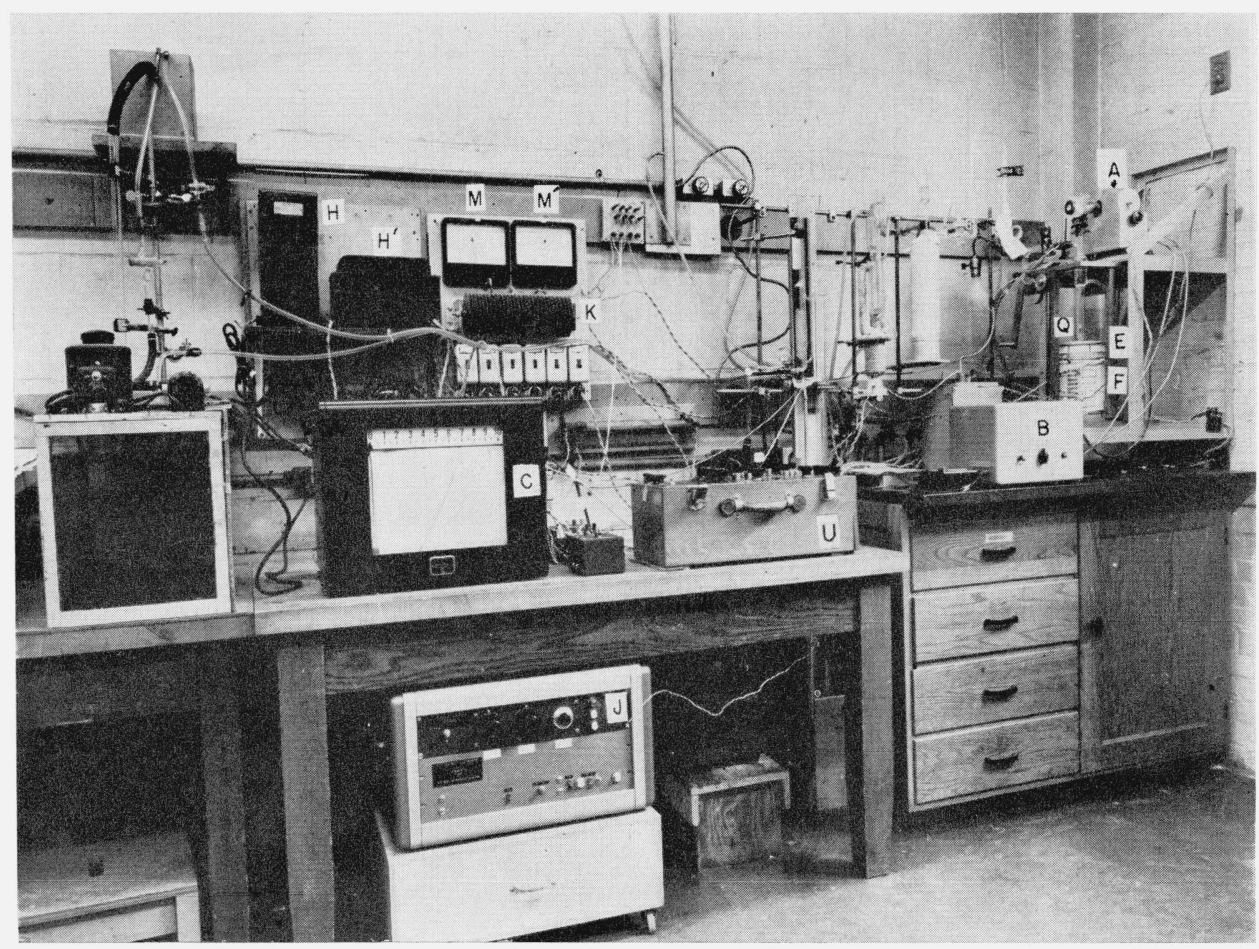

Figure 2. Polymer degradation equipment.

Letters correspond to the same parts as in figure 1, except $\mathrm{U}$, which indicates potentiometer for checking the temperature of the measuring thermocouple ( $\mathrm{R}$ in fig. 1). 
imbedded in the insulation of $\mathrm{E}$, and connected to the recorder through the potentiometer buckout $\mathrm{D}^{\prime}$. Power to the furnaces $\mathrm{F}$ and $\mathrm{E}$ is supplied from the voltage regulators $H$ and $H^{\prime}$, respectively, and is controlled by the variable autotransformers $\mathrm{G}$ and $\mathrm{G}^{\prime}$. The power to the lower furnace is, in addition, rectified by the bridge rectifier $\mathrm{K}$. It passes through the resistance $\mathrm{N}$, and is controlled by the electronic thermostat $J$ to maintain the constant temperature. The currents fed into $\mathrm{F}$ and $\mathrm{E}$ are read by means of ammeters $\mathrm{M}$ and $\mathrm{M}^{\prime}$.

The balance, known as the "Elmic" recording balance, is a modification of an instrument described earlier by Theodore Gast [4]. It makes use of a torsion suspension and a feedback circuit with an electrodynamometer type of actuation. It has four ranges, $10,5,2$, and $1 \mathrm{mg}$ full scale, the reading being indicated on a meter. For continuous recording, as in the present equipment, a $10-\mathrm{mv}$ recorder is connected to the balance.

The furnace and vacuum system have previously been described $[1,2]$ in detail. The electronic thermostat [5] consists basically of a resistance-bridge sensing unit, the output from which is amplified and used with a time-proportional control circuit to control the power supplied to the furnace.

The recorder is a standard 3-channel, 10-mv, commercial type. A photograph of a part of the recorder chart is shown in figure 3 . The chart gives a record of the first $7 \mathrm{hr}$ of operation of an experiment, which is described later, on the rate of degradation of polymethylene at $362.4^{\circ} \mathrm{C}$. The horizontal scale in the chart can be used to calculate the loss in weight and the temperature of the thermocouples S and R (see fig. 1). The vertical scale shows the duration of the experiment. Lines I and II represent records of temperatures indicated by thermocouples $S$ and $R$, respectively. Line III represents a record of the loss of weight of the sample being heated. In this as well as in all the other rate experiments described in this paper, the 5-mg fullscale range of the electronic balance was used.

The procedure used in the present work is in general the same as that used previously with the spring balance, and has been described in detail $[1,2]$. In the present method it also required about $15 \mathrm{~min}$ from the time the furnace was raised in position, for the thermocouple $\mathrm{R}$ to reach the required temperature (fig. 3).

\section{Temperature Measurement}

In the previous work on rates of thermal degradation of polymers the cooling-end effect of furnace $\mathrm{F}$, figure 4 , was overcome by adding a smaller furnace $\mathrm{E}$ on top of furnace $\mathrm{F}$, and keeping the temperature at the interface $\mathrm{L}$ constant by means of thermocouples $W$ and ' $W$ ' in conjunction with an electronic thermostat [5] not shown in the figure. It was assumed that by this means it would be possible to maintain about the same temperature in crucible $\mathrm{Q}$ as that indicated by thermocouple $\mathrm{R}$. To check this, a series of blank experiments was carried out in which a chromel-constantan thermocouple $V$ (shown in fig. 4), was placed inside the crucible $\mathrm{Q}$ and pressed against the bottom of the crucible by means of a platinum ring. The crucible was suspended in the glass apparatus in the same position as would be used in an actual experiment.

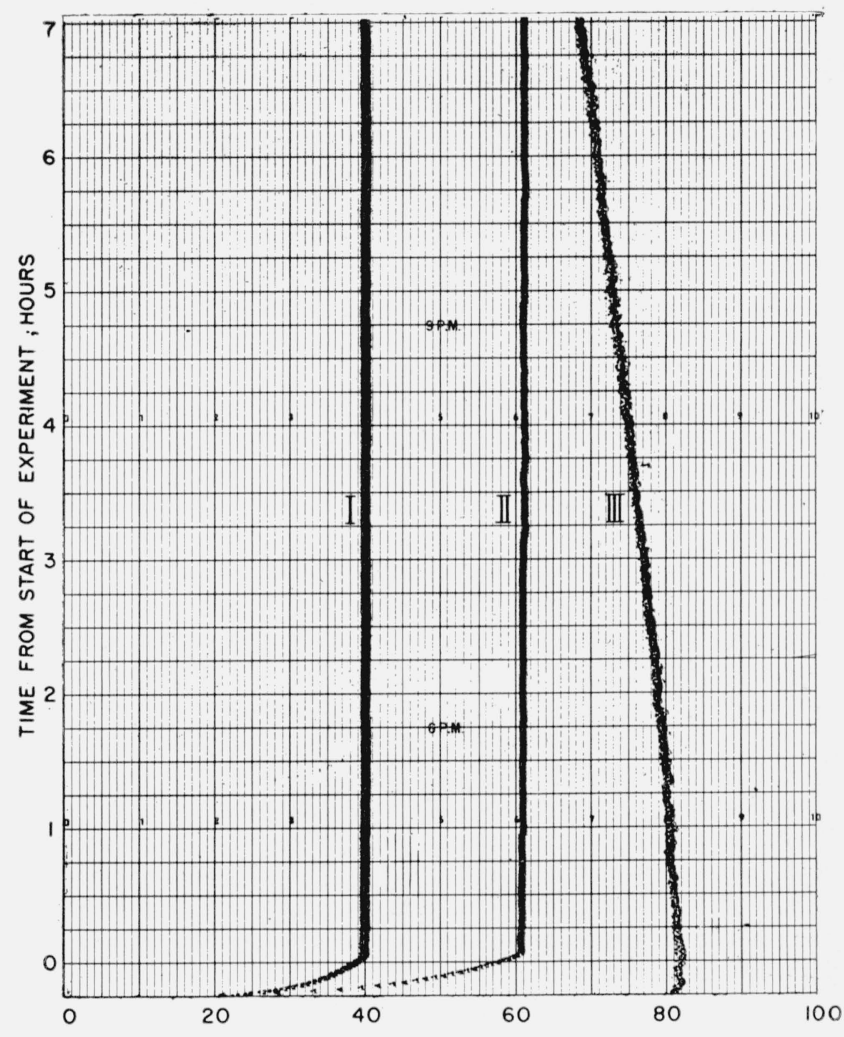

FIGURE 3. Part of recorder chart, indicating the first $7 \mathrm{hr}$ of operation of an experiment on the degradation of polymethylene at $362.4^{\circ} \mathrm{C}$

Temperature indicated by thermocouple $\mathrm{S}$ (I); temperature indicated by thermocouple R (II); loss of weight of sample (III).

When operating under the experimental conditions previously used, there was a temperature difference between thermocouples $\mathrm{R}$ and $\mathrm{V}$ of about $-14^{\circ} \mathrm{C}$. However, it was found that the thermocouples $V$ and $R$ could be made to record the same temperature for a distance of 2 to $3 \mathrm{~mm}$ between the crucible and thermocouple $\mathrm{R}$ by adjusting the current input in the furnaces $\mathrm{E}$ and $\mathrm{F}$. The system was then calibrated by measuring the required currents for a series of temperatures and constructing corresponding current-temperature curves in the range $200^{\circ}$ to $400^{\circ} \mathrm{C}$. These curves were followed in the experimental work on rates described. Temperature control at the interface L (fig. 4) was not used.

\section{Materials Used}

The following materials were used in this investigation:

1. Polystyrene. Prepared thermally by the Dow Chemical Co. Average molecular weight of 230,000, as determined by the osmotic pressure method. 


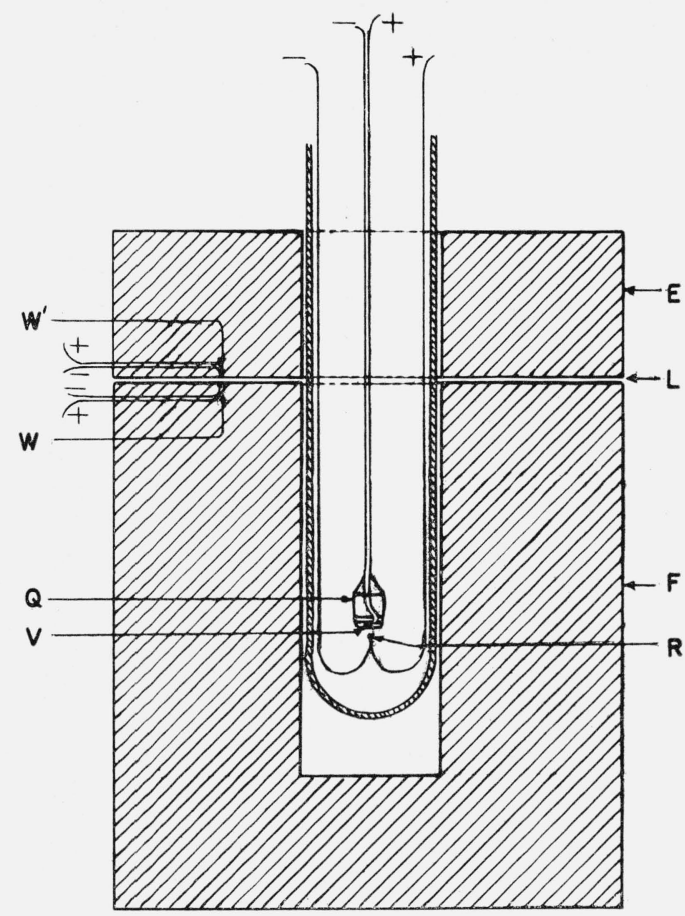

Figure 4. Details of furnace and control of uniformity of temperature.

E, Upper furnace; F, Lower furnace; Q, platinum crucible; R, V, W, and $\mathrm{W}^{\prime}$, chromel-constantan thermocouples.

2. Poly ( $\alpha$-methylstyrene). Prepared thermally by the Dow Chemical Co. by low-temperature polymerization. Molecular weight by light scattering, 350,000 .

3. Polymethylene. Prepared according to the method described by Buckley and Ray [6] by decomposing diazomethane, using trimethyl borate as catalyst. Its molecules are unbranched without methyl groups, and of high molecular weight [7].

4. Polyethylene I. A pure grade polymer, highly branched, and of high molecular weight. Some of its properties are given in table $1 .^{5}$

5. Polyethylene II. A polymer of high purity, having a weight-average molecular weight of about 20,000 . Its branching characteristics are not known.

6. Poly(chlorotrifluoroethylene). Prepared without catalyst and having a weight-average molecular weight of 100,000 .

All these polymers, except number 4, are the same materials as those used previously in work on

TABLE 1. Properties of branched polyethylene $I^{\text {a }}$

\begin{tabular}{|l|r|}
\hline Weight-average molecular weight & 525,000 \\
Number-average molecular weight & 31,400 \\
Long-chain branching index & 18 \\
Density & 0.922 \\
Methyls per 1,000 carbons & 20.0 \\
Vinyls per 1,000 carbons & 0.04 \\
Trans-unsaturation per 1,000 carbons & .02 \\
Vinylidenes per 1,000 carbons & .15 \\
Carbonyls per 1,000 carbons. & .03 \\
\hline
\end{tabular}

a See footnote 5 . ${ }^{5}$ The author is indebted to F. W. Billmeyer, Jr., of the Polychemicals Depart-
ment of E. I. du Pont de Nemours and Co., Inc., for supplying this polymer and the information on its properties as given in table 1 . rates of thermal degradation at higher temperatures in the tungsten spring balance apparatus $[1,2,7,8,9]$. As in previous work, the samples were heated in a vacuum at $100^{\circ} \mathrm{C}$ to a constant weight before they were used in the rate experiments.

\section{Experimental}

\subsection{Rate Measurements}

All the experiments on thermal degradation were carried out in a vacuum of about $10^{-4} \mathrm{~mm}$ of mercury, obtained by means of an oil pump and mercury diffusion pump. Weights of the samples varied from 4 to $5 \mathrm{mg}$. The furnace was first heated to the operating temperature in preparation for an experiment, and then raised into position by means of an elevator for pyrolysis of the polymer sample. It ordinarily took about $15 \mathrm{~min}$ from the time the furnace was raised into position to the time when thermocouple R (figs. 1 or 4 ) indicated the operating temperature. The temperature remained constant throughout the experiment to within $\pm 0.1^{\circ} \mathrm{C}$. Zero time for a given experiment was taken as the time when this temperature was reached (fig. 3). At the end of an experiment the residue in the crucible was weighed in order to check on the weight loss indicated on the recorder chart. The two values differed by about \pm 3 percent. This difference is within the combined experimental errors involved in weighing small samples, particularly the residues, on a semimicrobalance used in this work and in reading the recorder chart. The balance weight was used in calculating the results and the error was distributed over the horizontal scale of the recorder chart.

All these polymers, except number 4 , are the same materials as those used previously in work on rates of thermal degradation at higher temperatures in the tungsten spring balance apparatus [1, 2, 7, 8, 9]. As in previous work, the samples were heated in a vacuum at $100^{\circ} \mathrm{C}$ to a constant weight before they were used in the rate experiments.

In figures $5,6,7$, and 8 , percentage volatilization is plotted as a function of time for polystyrene, poly$(\alpha$-methylstyrene), polymethylene, and polyethylene I, respectively. Generally the curves resemble those obtained for the same materials in the spring balance apparatus, except for the initial parts. Whereas in the previous work, which was carried out at much higher temperatures, the losses during the heating-up period were in some cases as high as 10 percent, the curves in figures $5,6,7$, and 8 , show practically no such initial losses.

Curves showing rates of degradation as a function of percentage of volatilization for the four polymers are shown in figures $9,10,11$, and 12 . The rates were calculated from the volatilization-time curves and are expressed either as percentage of sample ( $\mathrm{K}_{1}$-curves) or as percentage of residue ( $\mathrm{K}_{2}$-curves). In the case of polystyrene the $K_{1}$ curve is given only for $299.3^{\circ}$ (dash-and-dot line of fig. 9). This curve has a maximum at about 30 percent volatilization. In the previous work at higher temperatures [1] the maxima were between 35 - and 40 -percent volatiliza- 


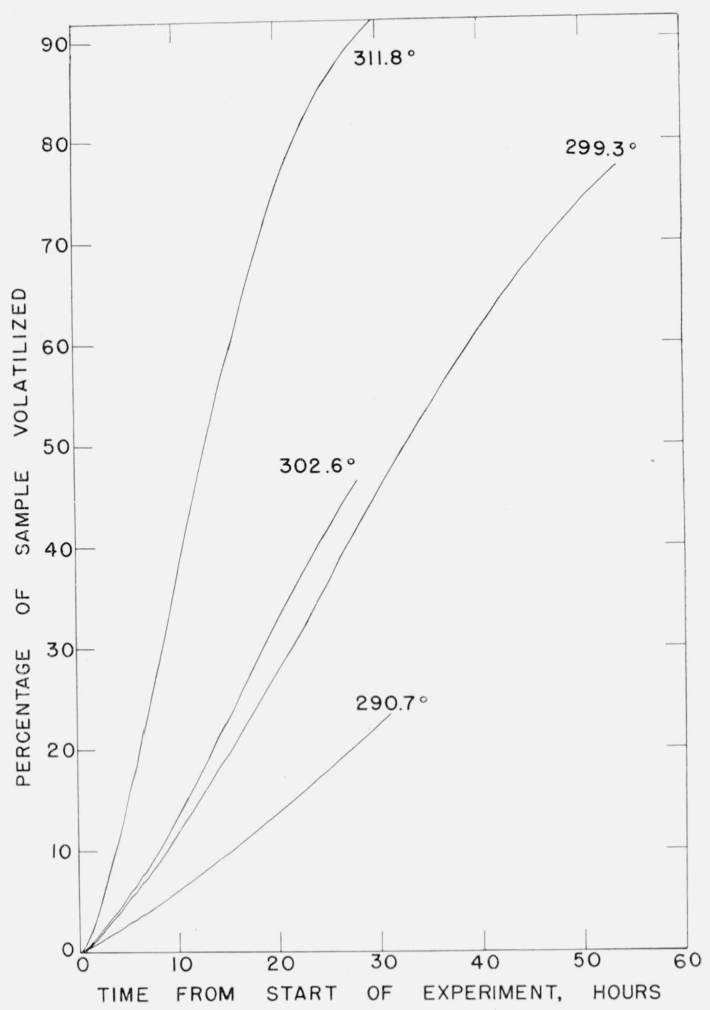

FiguRE 5. Thermal degradation of polystyrene.

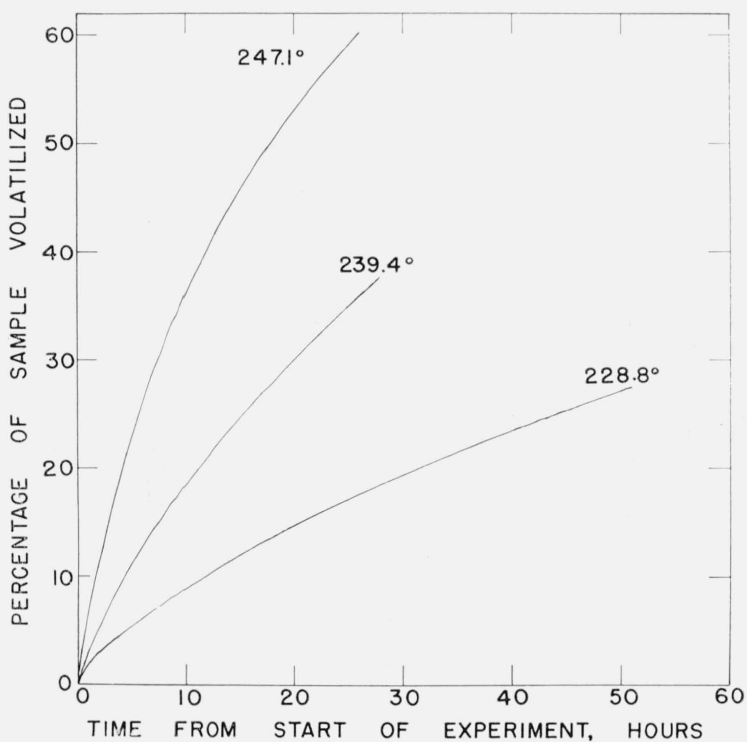

Figure 6. Thermal degradation of poly( $\alpha$-methylstyrene).

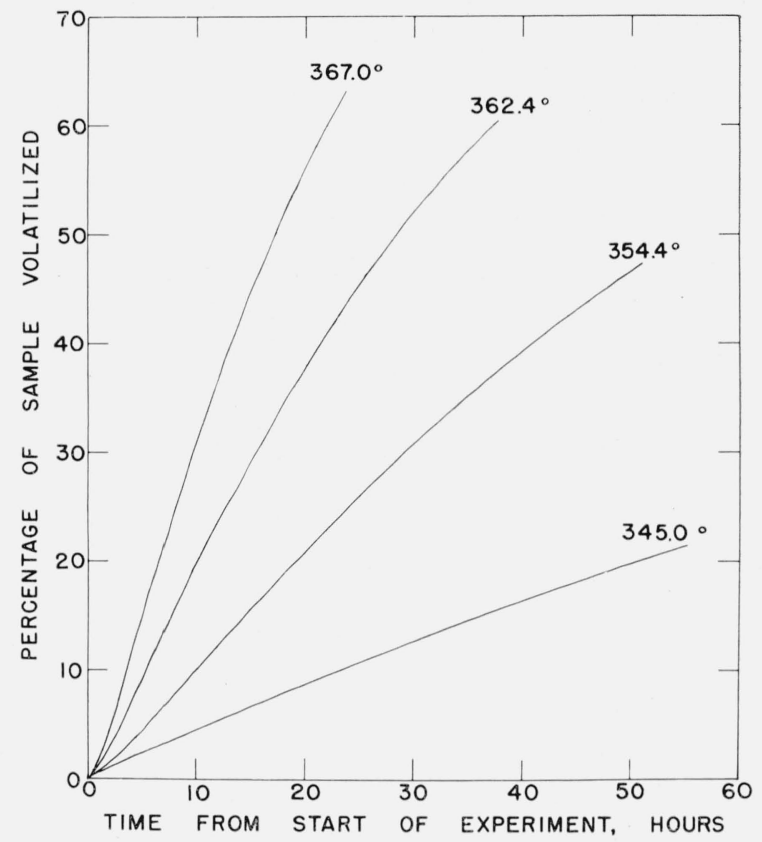

Figure 7. Thermal degradation of polymethylene.

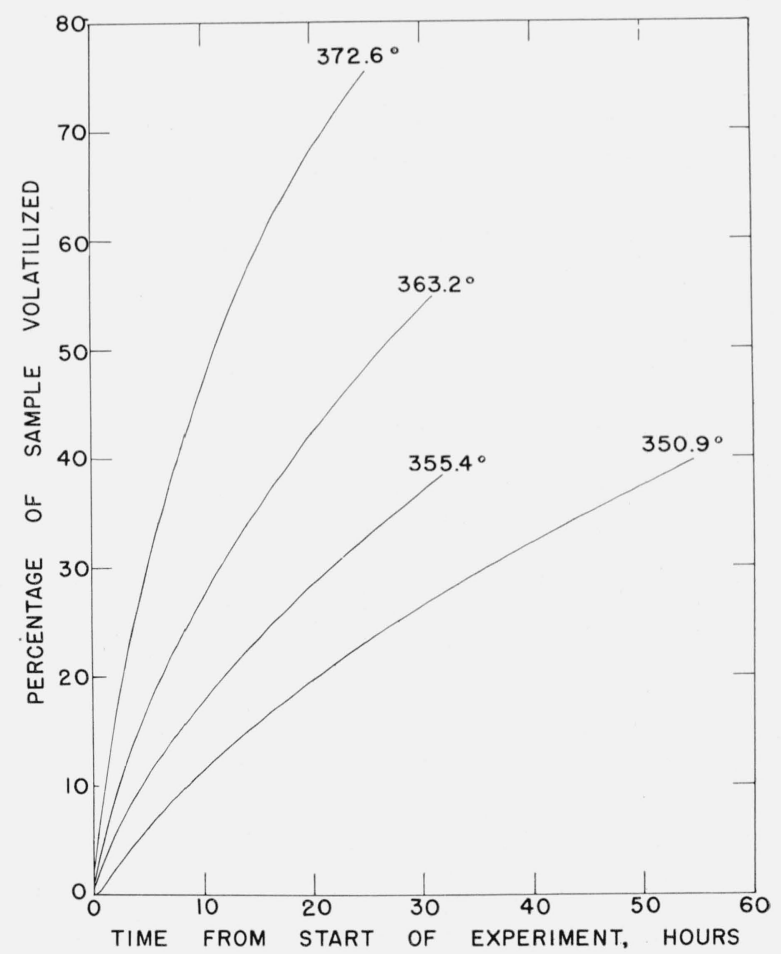

FIGURE 8. Thermal degradation of branched polyethylene. 


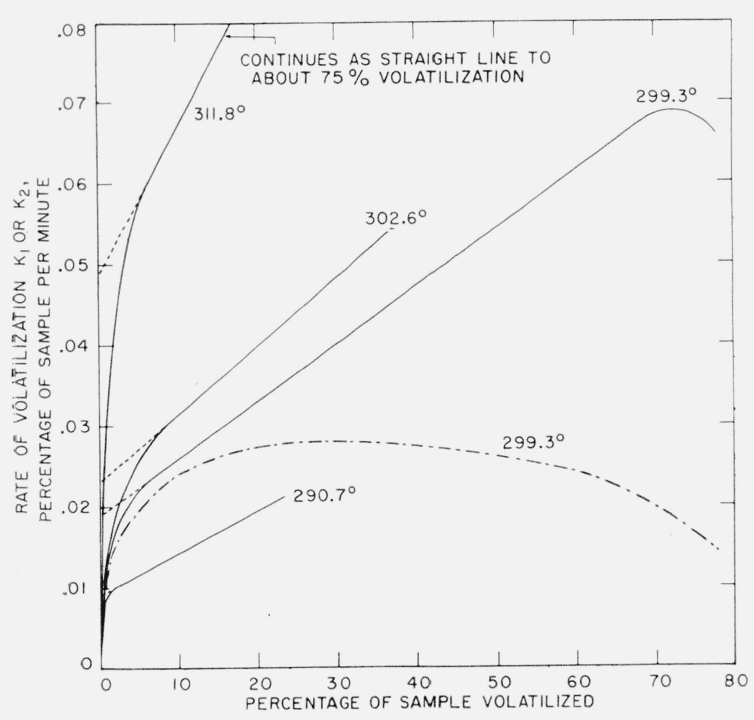

Figure 9. Rates of volatilization of polystyrene.

$$
\text { (-. . . - . - . } \left.\mathrm{K}_{1} \text { rate; }-\mathrm{K}_{2} \text { rates }\right)
$$

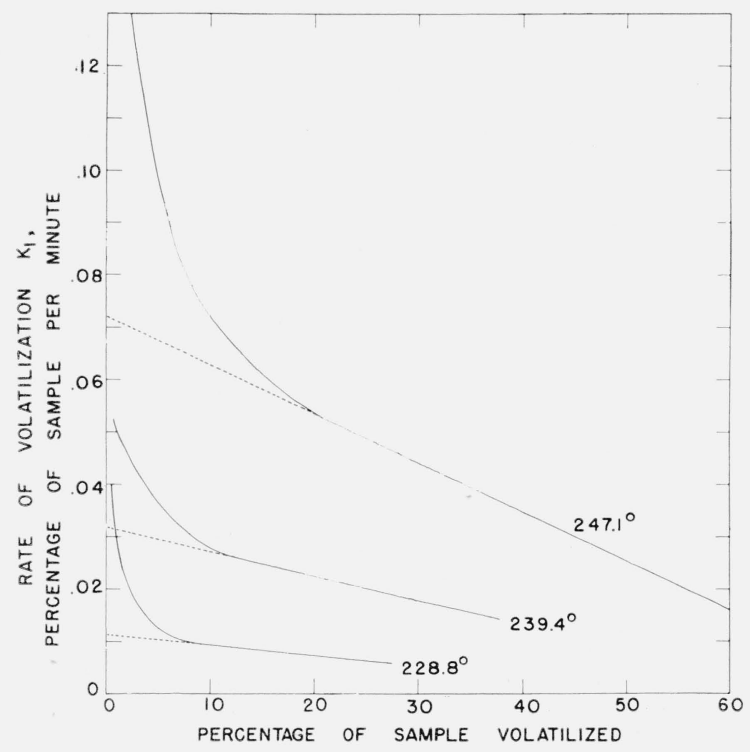

FIgURE 10. Rates of volatilization of poly( $\alpha$-methylstyrene). ( $\mathrm{K}_{1}$ rates)

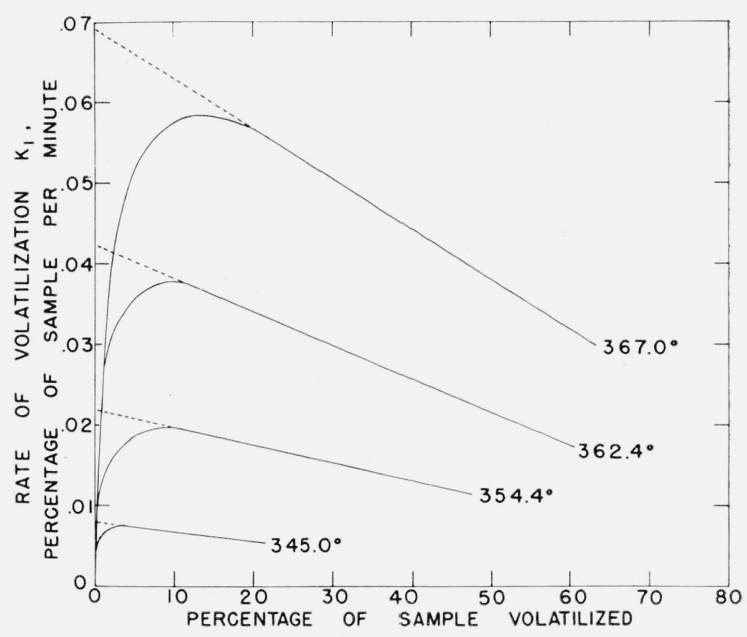

FIGURE 11. Rates of volatilization of polymethylene. ( $K_{1}$ rates)

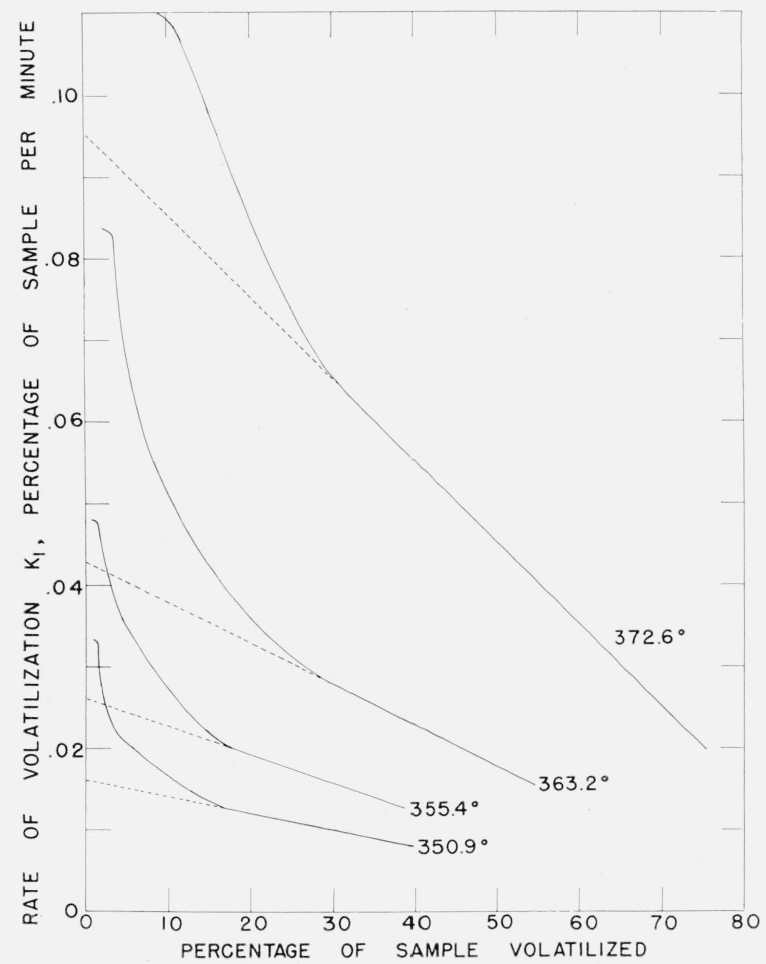

FIGURE 12. Rates of volatilization of branched polyethylene. ( $\mathrm{K}_{1}$ rates) 
TABLE 2.-Rates of thermal degradation of polymers

\begin{tabular}{|c|c|c|c|c|}
\hline Polymer & $\begin{array}{l}\text { Tem- } \\
\text { pera- } \\
\text { ture }\end{array}$ & $\begin{array}{c}\text { Duration } \\
\text { of ex- } \\
\text { periment }\end{array}$ & $\begin{array}{l}\text { Total } \\
\text { volati- } \\
\text { lized }\end{array}$ & $\begin{array}{l}\text { Initial } \\
\text { rate }\end{array}$ \\
\hline Polystyrene... & $\begin{array}{c}{ }^{\circ} \mathrm{C} \\
290.7 \\
299.3 \\
302.6 \\
311.8\end{array}$ & $\begin{array}{c}h r \\
31.0 \\
53.4 \\
27.8 \\
29.8\end{array}$ & $\begin{array}{c}\% \\
23.3 \\
77.6 \\
46.4 \\
92.1\end{array}$ & $\begin{array}{r}\% / \min \\
0.0090 \\
.0190 \\
.0230 \\
.0484\end{array}$ \\
\hline Poly ( $\alpha$-methylstyrene) & $\begin{array}{l}228.8 \\
239.4 \\
247.1\end{array}$ & $\begin{array}{l}51.0 \\
27.8 \\
26.0\end{array}$ & $\begin{array}{l}27.5 \\
37.8 \\
60.4\end{array}$ & $\begin{array}{l}.0110 \\
.0320 \\
.0720\end{array}$ \\
\hline Polymethylene . - & $\begin{array}{l}345.0 \\
354.4 \\
362.4 \\
367.0\end{array}$ & $\begin{array}{l}55.3 \\
51.0 \\
37.8 \\
23.8\end{array}$ & $\begin{array}{l}21.5 \\
47.6 \\
60.6 \\
63.1\end{array}$ & $\begin{array}{l}.0080 \\
.022 \\
.0424 \\
.0694\end{array}$ \\
\hline Polyethylene I... & $\begin{array}{l}350.9 \\
355.4 \\
363.2 \\
372.6\end{array}$ & $\begin{array}{l}54.5 \\
31.0 \\
31.0 \\
25.0\end{array}$ & $\begin{array}{l}39.6 \\
38.6 \\
54.7 \\
75.3\end{array}$ & $\begin{array}{l}.0160 \\
.0260 \\
.0430 \\
.0950\end{array}$ \\
\hline Polyethylene II_- & 360.2 & 31.0 & 51.8 & .051 \\
\hline Poly(chlorotrifluorethylene) _. . & 331.8 & 44.0 & 39.2 & .043 \\
\hline
\end{tabular}

tion. The $\mathrm{K}_{2}$ curves do not differ much in shape from those obtained previously in the spring balance. All the pertinent experimental data on rates of thermal degradation obtained in the present investigation are given in table 2 .

The $\mathrm{K}_{1}$ curves for poly ( $\alpha$-methylstyrene) in figure 10 differ up to about 20- to 25-percent volatilization, from the corresponding curves obtained at higher temperatures. Here the rates are initially high, then drop gradually in convex lines to about 8- to 20percent volatilization, and finally in straight lines in the manner of a first-order reaction. In the previous work at higher temperatures the rates were initially low, then rose gradually, reaching maxima between 20 - and 25-percent volatilization, and finally dropped in the same manner as shown in figure 10 . It is likely that this difference is due not to the difference in temperature but to the fact that in the present work the rates are much slower and are recorded automatically so that the details are more clearly delineated and the results are more dependable.

The $K_{1}$ curves for polymethylene (fig. 11) are similar to those obtained previously at higher temperatures. Polyethylene I (fig. 12) had not been studied previously. It would not be correct to compare the present results with those obtained previously for polyethylene II, because the two polymers are different in structure. On the other hand, a comparison between the $K_{1}$ curves for polyethylene I and for polymethylene shows a striking difference between the thermal behavior of these two polymers. The polymethylene rate curves start at the origin, rise to maxima at about 3- to 20 -percent loss, then fall in straight lines approaching zero at about 100 percent loss; while the polyethylene curves start at a fast rate, curve gradually in convex form to about 16 - to 30 -percent loss, and then fall in straight lines like the polymethylene curves. The explanation undoubtedly lies in the fact that volatilization in both polymers is due to fragments breaking off from the ends of the polymer chains; and, since the branched polyethylene has more ends, it volatilizes faster initially until most of the branches disappear.

The intercepts of the extrapolated straight parts of the rate curves $K_{1}$ or $K_{2}$ in figures $9,10,11$, and 12 are the apparent initial rates and indicate what the actual initial rates would have been were it not for rate-disturbing factors, such as rapid initial drop in the average molecular weight, presence of foreign groups at the ends of chains, or weak points [10] in the chains. However, the effects of these disturbing factors disappear after degradation proceeds to some extent.

The shape of the polystyrene rate curves (fig. 9) indicates that the reaction approaches a zero order. The pending benzene rings seem to have a stabilizing effect on the chains, so that the number of chainends and, therefore, the rate of formation of monomer dimer, and trimer at these ends by an unzipping process stays constant. In the case of poly $(\alpha-$ methlystyrene), the presence of quaternary carbons in the chain imparts instability to the chain, so that formation of new chain ends takes place at random and the reaction is of the nature of a first order one. In polymethylene and polyethylene the chains also break at random and the reaction is first order.

\subsection{Activation Energies}

The activation energies were obtained by plotting the logarithm of the apparent initial rates at various temperatures for any given polymer as a function of the inverse of the absolute temperature. The results are shown in figures $13,14,15$, and 16 for polystyrene, poly ( $\alpha$-methylstyrene), polymethylene, and polyethylene I, respectively. In figures 13,14 , and 15 are also plotted the results of the previous work $[1,2,8]$ carried out on the same materials at higher temperatures. Judging from the position of the dashed line (for the previous work) with respect to the solid line (for the present work), there seems to be a discrepancy in the two sets of temperatures to the extent of $17^{\circ}$ for polystyrene, $12^{\circ}$ for $\operatorname{poly}(\alpha-$ methylstyrene), and $14^{\circ}$ for polymethylene.

In the present work the temperatures were checked by actual measurements, as described earlier and illustrated in figure 4 . In the previous work it was erroneously assumed that there would be a region of uniform temperature within 2 to $3 \mathrm{~mm}$ distance above the thermocouple R (fig. 4). Actually the temperature of the crucible above $R$ must have been lower than that indicated by the thermocouple by the amounts shown above. A lowering of the temperature readings in the earlier work will not change in any way the shape of the volatilization-time curves, rate curves, or the initial rates, but will lower slightly the values of the activation energies involved. Thus the activation energies of polystyrene, poly $(\alpha-$ methylstyrene), and polymethylene, after correcting the temperatures, are 55,55 , and $73 \mathrm{kcal} / \mathrm{mole}$, respectively, as compared with the values of 58,58 , and $76 \mathrm{kcal} / \mathrm{mole}$ reported in the previous work for the same polymers. The results for branched polyethylene $\dot{I}$, shown in figure 16 , indicate an activation energy of $64 \mathrm{kcal}$. 


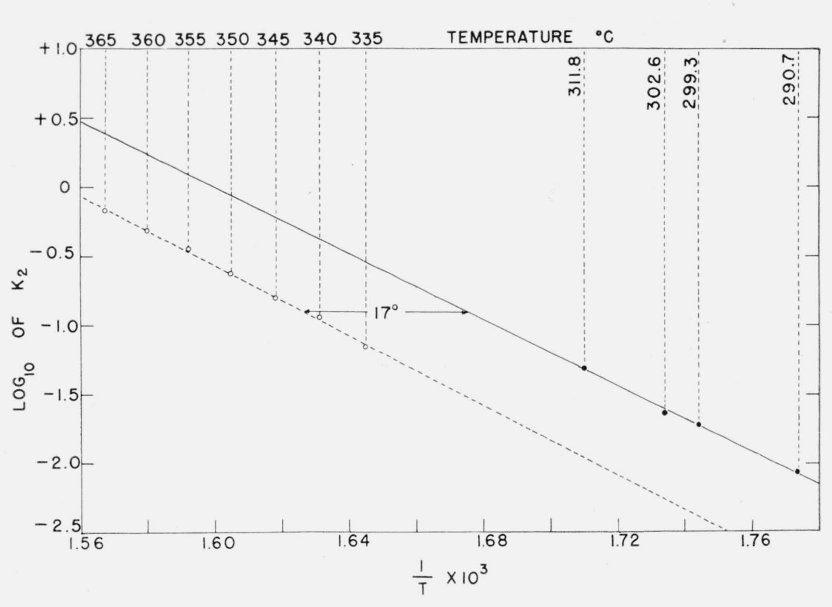

FIGURE 13. Activation energy of thermal degradation of polystyrene.

(Dashed line indicates previous work)

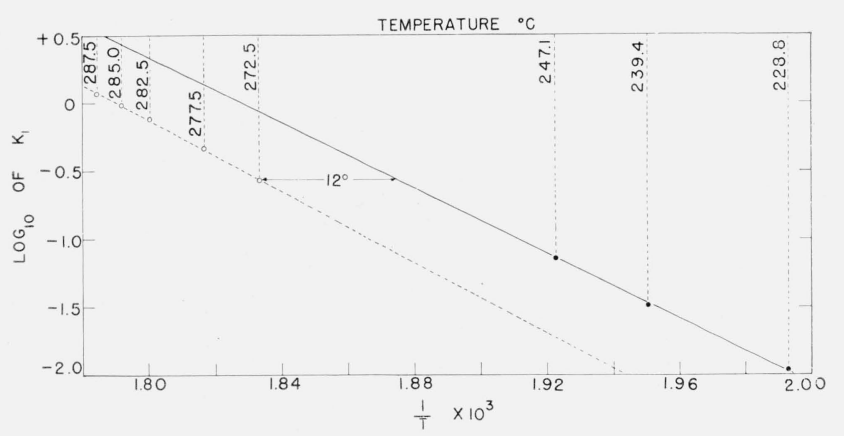

Figure 14. Activation energy of thermal degradation of poly ( $\alpha$-methylstyrene).

(Dashed line indicates previous work)

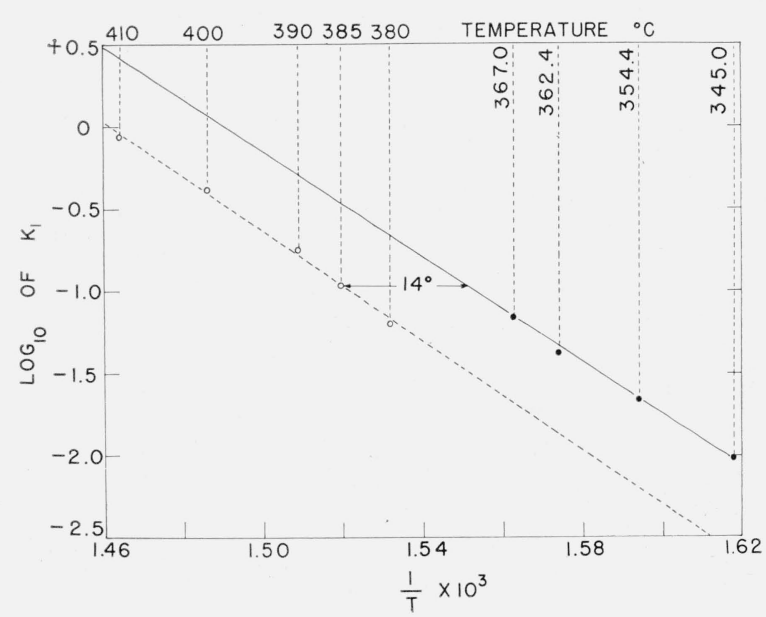

FIGURE 15. Activation energy of thermal degradation of polymethylene.

(Dashed line indicates previous work)

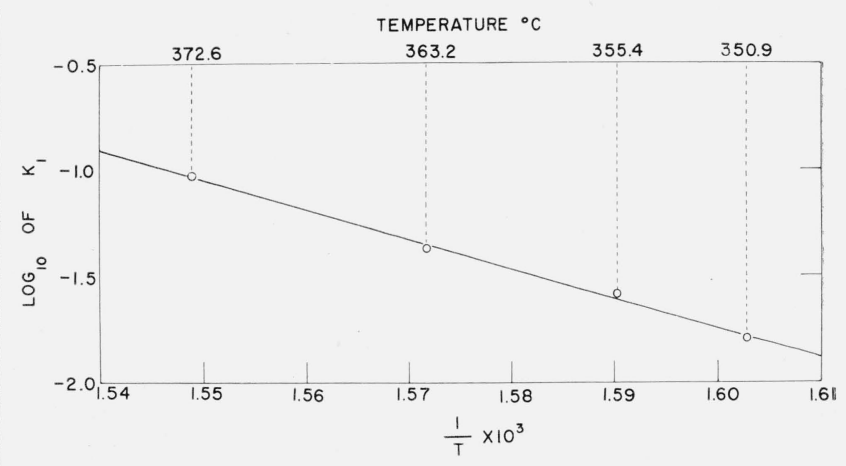

FIgure 16. Activation energy of thermal degradation of branched polyethylene.

\subsection{Poly(chlorotrifluoroethylene) and Low- Molecular-Weight Polyethylene}

As a further check on the temperature readings in the tungsten spring balance, two polymers, poly(chlorotrifluoroethylene) of average molecular weight weight 100,000 , and polyethylene II of molecular weight 20,000, were pyrolyzed in the electronic balance at relatively low temperatures. The results are shown in figures 17 and 18 . Pertinent data for these polymers are given in table 2 . The pyrolysis curves and the rate curves resemble closely those obtained previously $[1,9]$ for these two polymers at higher temperatures. However, when the results obtained in figures 17 and 18 and those obtained in the previous work are plotted in terms of logarithm of the initial rate as a function of inverse of absolute temperature, we find that the temperature readings in the previous work are too high by $14^{\circ}$ and $13^{\circ} \mathrm{C}$ for poly (chlorotrifluoroethylene) and polyethylene II, respectively, and the activation energies too high by $3 \mathrm{kcal} / \mathrm{mole}$ for both polymers.

\subsection{Correction of Previous Work}

On the basis of data in table 2 and the time and rate curves shown, it is suggested that corrections be made in the temperature data and activation energies obtained by the present author and his coworkers in their studies of rates of thermal degradation of a number of polymers determined previously in the tungsten spring balance. The suggested corrections for temperatures and the corrected activation energies are shown in table 3. The corrections given in this table for polystyrene of molecular weight 230,000 , poly ( $\alpha$-methylstyrene), polymethylene, poly(chlorotrifluoroethylene), and polyethylene of molecular weight 20,000 , are those found experimentally in the present investigation. The corrections for the other polymers shown in the table are those based on the average decrease of temperature and activation energies found experimentally in this work. These averages are $-14^{\circ} \mathrm{C}$ and $-3 \mathrm{kcal} / \mathrm{mole}$. No corrections are required for Teflon [10] since the temperatures for this polymer were calibrated by comparing the results obtained in the spring balance 


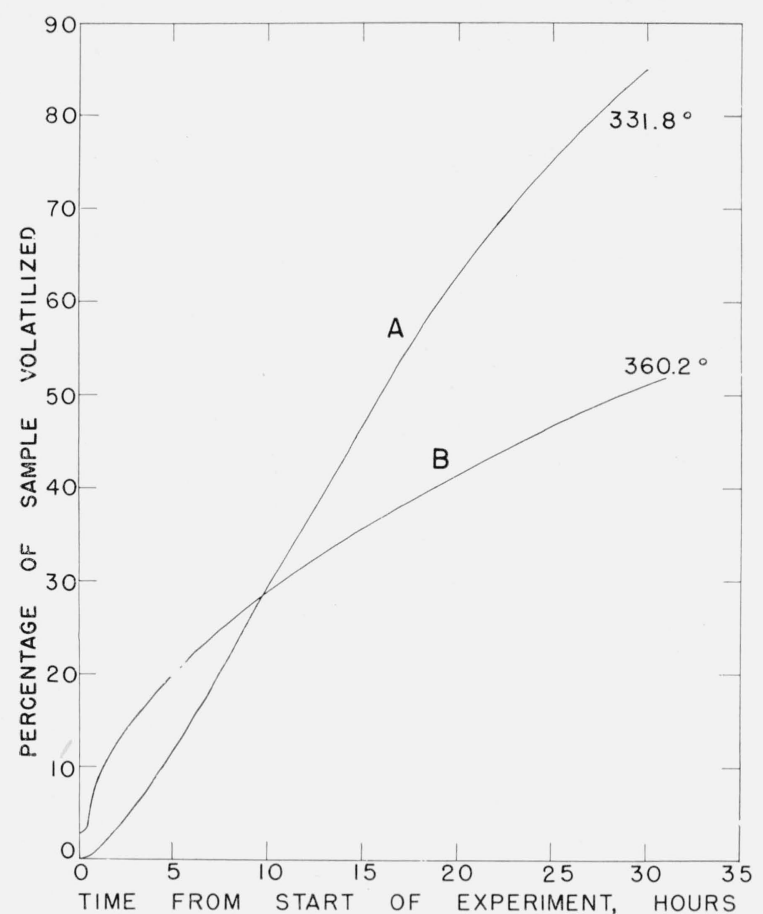

Figure 17. Thermal degradation of poly(chlorotrifluoroethylene) (A) and low-molecular-weight polyethylene $(B)$.

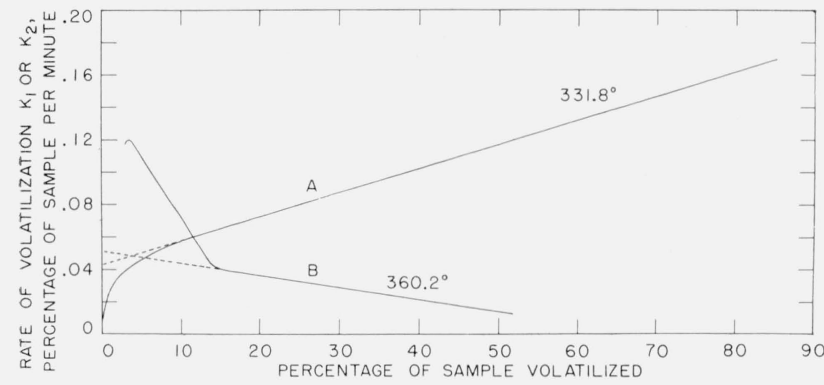

FIGURE 18. Rates of volatilization of polymers as a function of percentage volatilization.

Poly(chlorotrifluoroethylene) (A) in percent of residue per minute $\left(\mathrm{K}_{2}\right.$ rates); low-molecular-weight polyethylene (B) in percent of sample per minute ( $\mathrm{K}_{1}$ rates)

with those obtained by a pressure method. In the more recent work in the spring balance $[11,12]$ the furnace was calibrated in the same manner as described in the present work.

\section{Comparison of Rates Obtained by Several Investigators}

In view of the difficulties involved in measuring temperatures in a study of thermal degradation of polymers, there is a likelihood that there should be disagreements in the results obtained by various investigators. In figure 19 the results of rate studies obtained by Jellinek [13, 14], Grassie and Kerr [15], and the present author are compared. The results of all these investigators were obtained in vacuum,
TABLE 3. Corrections to be applied to experimental temperature and to activation energies in previous work

\begin{tabular}{|c|c|c|c|}
\hline Polymer & Reference & $\begin{array}{l}\text { Temper- } \\
\text { ature } \\
\text { correction }\end{array}$ & $\begin{array}{l}\text { Experi- } \\
\text { mental and } \\
\text { corrected } \\
\text { activation } \\
\text { energies }\end{array}$ \\
\hline $\begin{array}{l}\text { Polystyrene }(230,000) \\
\text { Polystyrene }(106,000) \\
\text { Polystyrene }(584,000) \\
\text { Polyethylene }(20,000) \\
\text { Poly ( } m \text {-methylstyrene) }\end{array}$ & $\begin{array}{l}{[1]} \\
{[1]} \\
{[1]} \\
{[1]} \\
{[2]}\end{array}$ & $\begin{array}{l}\circ C \\
-17 \\
-14 \\
-14 \\
-13 \\
-14\end{array}$ & $\begin{array}{l}k c a l / m o l e \\
55 \\
55 \\
55 \\
63 \\
56\end{array}$ \\
\hline $\begin{array}{l}\text { Poly ( } \alpha \text {-deuterostyrene) } \\
\text { Poly }(\alpha \text {-methylstyrene) } \\
\text { Hydrogenated polystyrene- } \\
\text { Poly (methyl methacrylate) A } \\
\text { Poly (methyl methacrylate) B }\end{array}$ & $\begin{array}{l}{[2]} \\
{[2]} \\
{[2]} \\
{[2]} \\
{[2]}\end{array}$ & $\begin{array}{l}-14 \\
-12 \\
-14 \\
-14 \\
-14\end{array}$ & $\begin{array}{l}55 \\
55 \\
49 \\
30 \\
52\end{array}$ \\
\hline $\begin{array}{l}\text { Poly(methyl acrylate) } \\
\text { Polymethylene } \\
\text { Polypropylene } \\
\text { Polyisobutylene } \\
\text { Polybenzyl }\end{array}$ & $\begin{array}{l}{[2]} \\
{[8]} \\
{[8]} \\
{[8]} \\
{[8]}\end{array}$ & $\begin{array}{l}-14 \\
-14 \\
-14 \\
-14 \\
-14\end{array}$ & $\begin{array}{l}34 \\
72 \\
58 \\
49 \\
50\end{array}$ \\
\hline $\begin{array}{l}\text { Poly ( } \beta \text {-deuterostyrene) (high mole- } \\
\text { cular weight) } \\
\text { Poly (chlorotrifluoroethylene) } \\
\text { Poly }(\alpha, \beta, \beta \text {-trifluorostyrene) } \\
\text { Poly (p-xylylene) }\end{array}$ & $\begin{array}{l}{[8]} \\
{[9]} \\
{[9]} \\
{[9]}\end{array}$ & $\begin{array}{l}-14 \\
-14 \\
-14 \\
-14\end{array}$ & $\begin{array}{l}56 \\
57 \text { \& } \\
64 \\
73\end{array}$ \\
\hline
\end{tabular}

a In reference [9] the activation energy for poly (chlorotrifluoroethylene) is given as $66 \mathrm{kcal} / \mathrm{mole}$. This is a misprint and should have read $60 \mathrm{kcal}$. When reduced by 3 units the activation energy becomes 57 .

using polymers prepared without catalysts and having high molecular weights. The solid lines in figure 19 represent polystyrene, and the dash-and-dot lines represent poly ( $\alpha$-methylstyrene); also, the letters $J$, $\mathrm{G}$, and $\mathrm{M}$, in front of the temperatures indicate the work of Jellinek, Grassie, and Madorsky, respectively. Temperatures in parentheses represent the uncorrected temperatures obtained by the present author in the tungsten spring balance.

The polystyrene curves M-290.7 ${ }^{\circ}$ and M-311.8 are the same as those given in figure 5. Curve $\mathrm{G}-290^{\circ}$ was obtained by Grassie and Kerr [15] on a sample of polystyrene (S-3), prepared without a catalyst and having a molecular weight of over 300,000 . Their rate apparatus consisted of a dynamic molecular still heated electrically [16]. The $\mathrm{G}-290^{\circ}$ curve is very close to the $\mathrm{M}-311.8^{\circ}$ curve, so that the temperature given by Grassie and Kerr is at least $20^{\circ}$ lower than the one obtained in the electronic balance in the present work. The M-290.7 curve lies far below the $\mathrm{G}-290^{\circ}$ curve. At higher temperatures the $\mathrm{J}-364^{\circ}$ curve was obtained by Jellinek for a polystyrene sample $\left(\mathrm{F}_{I I}\right)$, prepared without catalysts and having a molecular weight of $200,000[13,14]$. He used a quartz spring balance. Curves $\mathrm{M}-328^{\circ}\left(345^{\circ}\right)$ and $\mathrm{M}-348^{\circ}\left(365^{\circ}\right)$ were obtained by the present author on a thermally prepared polystyrene of molecular weight 230,000 , using a tungsten spring balance [1]. Position of $\mathrm{J}-364^{\circ}$ is close to that of $\mathrm{M}-328^{\circ}\left(345^{\circ}\right)$ and is far below that of M- $348^{\circ}\left(365^{\circ}\right)$ curve. Thus Jellinek's temperature reading is about $30^{\circ}$ to $32^{\circ}$ higher than that of the present author and about $50^{\circ}$ higher than that of Grassie and Kerr.

In the case of poly ( $\alpha$-methylstyrene) Jellinek [14] pyrolyzed a 70,000 molecular weight sample in the quartz spring apparatus and obtained a volatiliza- 


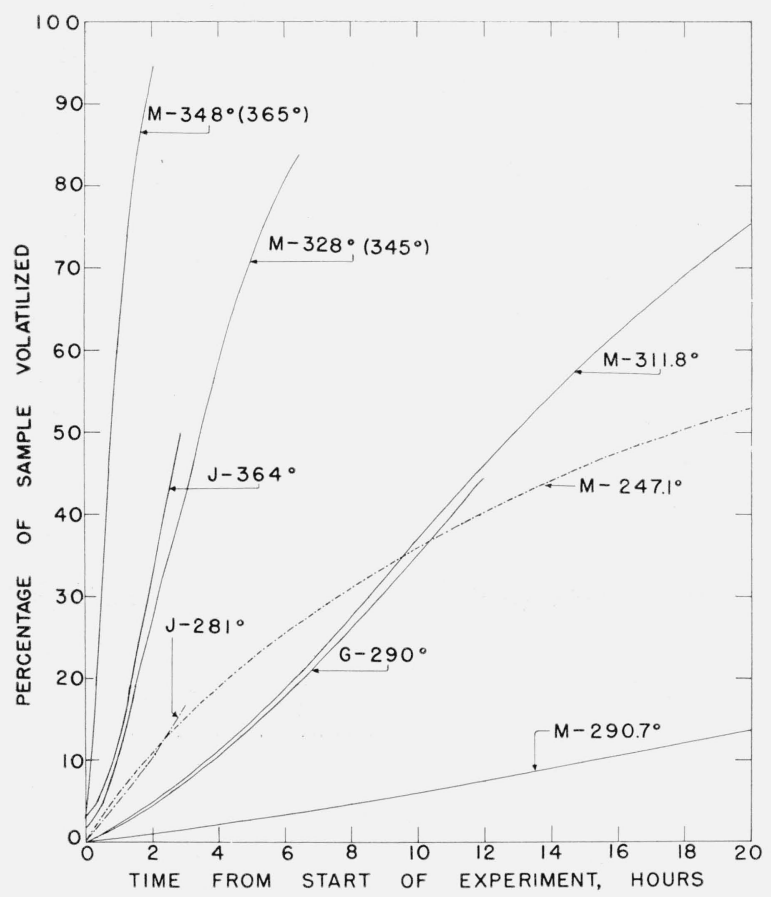

FiguRE 19. Comparison of results obtained by various investigators on thermal degradation of polymers at various temperatures.

-, Polystyrene; - . . . _ . ., poly ( $\alpha$-methylstyrene). The letter in front of each temperature refer to the investigators: G, Grassie; J, Jellinek; M, Madorsky. Temperatures in parentheses are uncorrected temperatures obtained in the spring-balance pyrolysis apparatus.

tion-time curve shown in figure 18 as $\mathrm{J}-281^{\circ}$. The curve M-247. $1^{\circ}$ is the same as the $247.1^{\circ}$ curve given above in figure 6 . Jellinek's temperature reading appears to be about $34^{\circ}$ higher than the one obtained by the present author using the electronic balance.

It is believed that the principal reason for the differences between the various investigators lies in measurement of the temperature of the sample. As shown earlier in this paper, this measurement is very sensitive to the maintenance of a uniform temperature in the zone where the sample and the thermocouple are located and to the relative position of these two in this zone.

\section{Discussion and Conclusions}

A quantitative determination of rates, and consequently of activation energies, in the study of thermal degradation of polymers by the pressure or loss-of-weight method is beset by many difficulties. The following are some of the more serious difficulties.

1. Spattering caused by the bursting of bubbles of gaseous products of degradation which accumulate in the polymer sample.

2. Delay in the vaporization of volatile products due to slow diffusion through the solid or semisolid polymer.
3. The difficulty of maintaining a uniform temperature through the polymer sample due to its poor heat conductivity. This is further aggravated by the fact that the degradation reactions involved are endothermic in most cases.

4. The difficulties associated with measurement of temperature.

5. Uncertainties in temperature and rate observation during the initial heating-up period.

With regard to points 1,2 , and 3 , the difficulties were reduced to a minimum in the present work as well as in the earlier work by limiting the weight of the samples to about $5 \mathrm{mg}$ or less. As to point 4, precautions were taken in the present work to obtain a uniform temperature in the region where the thermocouple and the sample are located in close proximity to each other. The difficulties encountered during the initial stage of degradation, referred to in point 5 , were reduced in this work to a minimum by operating at low temperatures, so that very little loss by volatilization took place during the 15 -min heatingup time.

A study of rates of degradation at low temperatures, in conjunction with automatic recording of loss of weight and of temperature, not only renders the observations more accurate, but also reveals details that are otherwise masked by a rapid rate of volatilization at high temperatures. This is particularly true for polyethylene and poly $(\alpha$-methylstyrene) where the actual initial rates of degradation are very high.

\section{References}

[1] S. L. Madorsky, J. Polymer Sci. 9, 133 (1952).

[2] S. L. Madorsky, J. Polymer Sci. 11, 491 (1953).

[3] S. L. Madorsky, Rev. Sci. Instr. 21, 393 (1950).

[4] Theodore Gast, Feintechnik 53, 172 (1949).

[5] F. A. Ransom, Control Eng. 1, 1 (1954); also, U.S. Patent 2,376,488.

[6] G. D. Buckley and N. H. Ray, J. Chem. Soc. 1952, 3701.

[7] L. A. Wall, S. L. Madorsky, D. W. Brown, S. Straus, and R. Simha, J. Am. Chem. Soc. $\boldsymbol{7 6 ,} 3430$ (1954).

[8] S. L. Madorsky and S. Straus, J. Research NBS 53, 361 (1955) RP2553.

[9] S. L. Madorsky and S. Straus, J. Research NBS 55, 223 (1955) RP2624.

[10] S. L. Madorsky, V. E. Hart, S. Straus, and V. A. Sedlak, J. Research NBS 51, 327 (1953) RP2461.

[11] S. Straus and S. L. Madorsky, J. Research NBS 61, 77 (1958) RP2888.

[12] S. L. Madorsky and S. Straus (submitted for publication in the J. Polymer Sci.).

[13] H. H. G. Jellinek, J. Polymer Sci. 3, 850 (1948).

[14] H. H. G. Jellinek, J. Polymer Sci. 4, 13 (1949).

[15] N. Grassie and W. W. Kerr, Trans. Faraday Soc. 53, 234 (1957)

[16] N. Grassie and H. W. Melville, Proc. Royal Soc. (London) [A] 199, 1 (1949).

Washington, December 5, 1958. 